\title{
Istilah Teknis dan Permasalahannya dalam Penerjemahan
}

\author{
Muhamad Nur ${ }^{1}$
}

\begin{abstract}
Term is a word or word-combination which denotes the notion of a special realm of communication in science, industry, technology, art, in a definitive field of knowledge and human activity, that is a special purposes linguistic unit (Лейчик 2007). In this context, the article develops the analyses of writer's master thesis about the translation of Indonesian terminology standardization directory for computer application 'Panduan pembakuan istilah penggunaan komputer dengan aplikasi komputer berbahasa Indonesia' that were set up by the TIM INPRES 'the Presidential directive teams' of Indonesia, Number 2/2001. The analyses result was that identifiable numerous approaches of equivalent, and these categorizable inconsistance in the translation process. Therefore, the message of source language (English) could not comprehensively be expressed in the target language (Indonesian). Analyses development in the article is tend toward the reviewing of technical terms existence etimologically-theoretically, referring to the International Terminology Standardization, International Standardization Organization (ISO), and Handbook of Terminology in relation to the message sense of technical terms in translation.

Thus, the technical terms in the translation context are bounded by four dimensions; concept, object, term and definition referring to the semiotic triangle as the terminologists' additional dimension. Where, the pyramid was extended by the dimension of definition resulting four intersections to represent the concept. Accomodating the concept of technical terms can only be handled through the adoption approach of phonetic and semantic adaptation to keep the equivalent message of two different languages.
\end{abstract}

Key Words: technical terms, terminology standardization, semiotic triangle, translation, adoption approach.

\section{Pendahuluan}

Istilah teknis sebagai unit terminologi atau peristilahan yang tergolong ke dalam bahasa untuk Tujuan Khusus 'Language for Specific Purposes LSP'(Gibbon, 1999, Guidelines for Terminology Policies - Paris, 2005) merupakan bagian dari Lingusitik Terapan 'Applied Linguistic' (C.Lionhardt,

\footnotetext{
${ }^{1}$ Staf Akademik STMIK Bumigora Mataram, NTB; Pembina Mata Kuliah Bahasa Inggris Tujuan Khusus (English for Information and Technology).
} 
2001). Istilah teknis bukan hanya permasalahan kita, baik secara personal, komunal maupun nasional, bahkan menjadi permasalahan internasional karena tidak sedikit negara mengalami permasalahan terminologi. Sebagaimana yang telah dibahas melalui kegiatan lokakarya pada 'The 6th Workshop on Asian Language Resources' tentang “Terminologi bahasa teknis yang dialami bahasa nasional negara-negara di kawasan Asia. Lokakarya tersebut, menyoroti masalah perbedaan pendekatan dalam mengadopsi istilah rekayasa bahasa teknis (Matsuda dkk, 2008). Matsuda yang bernama lengkap Makiko Matsuda berasal dari Nagaoka University of Technology Jepang merupakan salah seorang narasumber dalam kegiatan lokakarya tersebut.

Menurut Matsuda, pengembangan peristilahan dalam dunia pendidikan, ilmu dan teknologi merupakan kunci menuju pembentukan masyarakat berpengetahuan. Menurut Matsuda, terdapat dua pendekatan dalam adopsi istilah tehnik, yakni "adopsi fonetis" (atau dengan transliterasi istilah yang dipinjam) dan "adopsi semantik" (dimana makna terungkap dengan menggunakan kata-kata bahasa sumber). Proporsi terhadap dua opsi yang terdapat dalam perangkat terminologi setiap negara (atau bahasa) menunjukkan perbedaan substantif dan nampak merefleksikan kebijaksanaan bahasa negara dan pengaruh aneka bahasa asing terhadap bahasa sasaran (host language).

\subsection{Batasan "Istilah"}

Menurut Kamus Besar Bahasa Indonesia (KBBI, 2007: 446, ed. ke-3 dan Pedoman Pembentukan Istilah, 2007: 9), istilah adalah kata atau gabungan kata yang dengan cermat mengungkapkan makna konsep, proses, keadaan, atau sifat yang khas di bidang tertentu. Dalam jabaran selanjutnya, dijelaskan bahwa istilah mempunyai konteks khusus dan konteks umum. Istilah khusus merupakan istilah yang pemakaiannya dan/atau maknanya terbatas pada bidang tertentu, sedangkan istilah umum merupakan istilah yang menjadi unsur bahasa yang digunakan secara umum. Namun, terkait dengan artikel ini, pembahasan difokuskan pada istilah khusus yang selanjutnya disebut dengan istilah teknis karena maknanya terbatas pada bidang tertentu atau khusus.

Mengacu kepada beberapa literatur asing, sebutan istilah itu pada umumnya disandingkan dengan kata teknis 'technical term' sebagai unit terminologi (baca Gibbon, 1999, Matsuda, 2008, Pinchuck, 1977, Schmitz, 2005) yang batasannya dapat diakomodasi sebagai "perancangan konsep yang tetap dalam sebuah bahasa khusus melalui ekspresi Linguistik" (ISO 1087 dalam Nicole Keller, 2010). 
Sebagai sebutan istilah teknis, baik menurut KBBI maupun literatur asing terdapat dua hal sebagai unsur kesamaan yang dapat diacu, yakni menyangkut bidang tertentu atau khusus dan makna khusus yang terikat oleh konsep.

\subsection{Arti Term dalam Sistem Terminologi}

Kata term berasal dari bahasa Latin terminus, yang berarti 'tanah bertanda', atau 'batas'. Selanjutnya makna terminus dalam penjelasannya adalah dewa dari tanah bertanda dan batu pembatas pada zaman Romawi Kuno dan areal yang dilindungi kesakralannya (Селіванова 2010, dalam Tatjana Rusko dan Santalka, 2010).

Term dalam konteks kebahasaan adalah sebuah kata atau kombinasi kata yang menandakan gagasan dalam bidang pengetahuan dan aktifitas manusia, yakni tujuan khusus unit linguistik (Лейчuк 2007). Kemudian, terminologi komputasi dipahami menjadi kesepakatan istilah yang membentuk sistem khusus leksis terminologis dalam bahasa Inggris. Sistem terminologis sebagai sebuah kesepakatan istilah dibentuk menjadi dasar satu konsep dan merefleksikan hubungan antara konsep ranah khusus ilmu dan teknologi (Лейчик 2007, Gediminas dan Santalka, 2010).

Pandangan lain yang lebih jelas lagi tentang definisi istilah adalah bahwa istilah terkait dengan konsep khusus dalam bidang subjek tertentu (Papel, 2004).

\subsection{Penggunaan Definisi Istilah}

Istilah yang digunakan dalam pandangan ini seperti yang dinyatakan oleh Gibbon adalah dalam beragam konteks dan mempunyai kegunaan yang pasti harus dalam bentuk kata tunggal tapi juga dalam bentuk seperangkat kata-frase tetap- yang digunakan hanya untuk menunjukkan konsep khusus. Bagi sebagian kalangan terminolog, istilah adalah hanya satu ekspresi kata. Hal ini mengarah pada beberapa kesulitan karena sebagian bahasa tidak membentuk istilah dengan kata majemuk tapi dengan kolokasi atau sanding kata. Keuntungan penggunaan istilah dengan hanya satu ekspresi kata adalah batasannya lebih mudah dikenal (baik secara elektronik maupun secara manual). Meskipun demikian, semua kalangan terminolog akan menerima frase yang terdiri dari dua atau tiga kata sebagai sebutan istilah (Gibbon, 1999). 
70| Mabasan - Vol. 5, No. 1, Januari-Juni 2011

\subsection{Ilmu Terminologi - Sekilas lebih Dekat}

Istilah terminologi adalah terminologi itu sendiri yang digunakan dalam beberapa pengertian yang berbeda. Yang paling sering digunakan dewasa ini adalah bahwa terminologi merupakan "kosa kata dari bidang subjek khusus" (Sager, 1990). Hal ini juga diperkuat oleh definisi Organisasi Standardisasi Internasional (ISO) yang mendefinisikan terminologi sebagai "seperangkat istilah yang merepresentasikan sistem konsep bidang subjek tertentu" (ISO 1087:1990, 1990). ISO mendefinisikan ini sebagai ilmu terminologi, yaitu "kajian ilmiah terhadap konsep dan istilah yang terdapat dalam bahasa khusus" (ISO 1087:1990, 1990).

Merujuk kepada batasan mengenai terminologi, seperti yang dinyatakan oleh Sagar maupun ISO serta terminolog lainnya adalah mempunyai prinsip yang sama dalam hal bahasa tertentu atau khusus. Bahasa khusus menyangkut istilah sebagai padanan dari kata term dalam unit terminologi, yang secara etimologi dapat dimaknakan sebagai unit linguistik yang dibatasi oleh konsep. Seperti halnya batasan terminus yang berarti batas untuk menjaga tempat sakral yang dilindungi sehingga mustahil mempunyai padanan dalam ranah umum atau bidang lain secara keilmuan kecuali melalui pendekatan adopsi baik secara fonetis maupun semantis untuk mempertahankan makna sebagaimana disinggung pada bagian lain.

\subsection{Sistem Konsep Menurut Para Ahli Terminologi}

Segitiga semiotik (gambar 1) sebagaimana yang dikenal pada kalangan linguis, menggambarkan hubungan antara sebuah obyek-yakni aneka benda seperti yang mereka persepsikan-relasi atau persepsi dari obyek oleh manusia, dan tanda yang digunakan untuk mengacu obyek yang dipersepsikan.

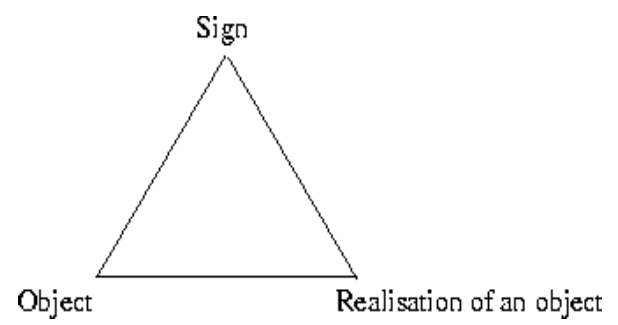

Gambar 1: Skematisasi segitiga semiotik

(diadaptasi dari Terminology for Spoken Language Systems) 
Yang mendasar menurut sudut pandang terminolog adalah konsep. Analisis konsep merupakan sentral dalam terminologi (Skuce dan Meyer, 2010). Lebih rinci menurut Gibbon dkk. (1990) bahwa obyek dikelompokkan sesuai dengan konsepnya dan hubungan yang terkait antara satu dengan lainnya. Inilah perbedaan mendasar antara leksikografi, yakni kumpulan tanda dan penyusunannya dengan merujuk pada standar leksikografis (seperti pengaturan alpabetis) dan terminografi, yakni kumpulan konsep dan dihubungkan oleh relasinya kemudian ditetapkan proses penyusunannya.

\subsection{Tambahan Dimensi oleh Terminolog pada Segitiga Semiotik}

Segitiga semiotik dikembangkan dari dimensi lain menurut sudut pandang para ahli terminologi (Suonuuti, 1997 dalam Gibbon 1999), seperti yang ditampilkan pada gambar 2. Piramid ini dikembangkan dari dimensi definisi yang dihasilkan dalam empat titik potong, yakni konsep, objek, istilah, dan definisi. Hubungan titik potong konsep (wujud objek), objek ('objek' pada gambar segitiga semiotik) dan istilah ('tanda' dalam segitiga semiotik tradisional) selebihnya sama dengan semiotik tradisional. Definisi sebagai hubungan baru harus dijelaskan.

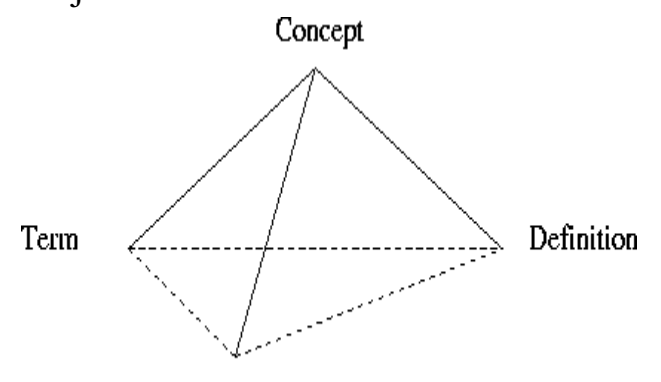

Object

\section{Gambar 2: Segitiga Semiotik yang Dikembangkan}

(Suonuuti, 1997)

Dari perspektif lain, definisi juga dipengaruhi oleh istilah karena sumber definisi harus menghindari definisi yang sirkular atau berputar. Hubungan antara istilah dengan definisi adalah dua arah.

Masih menurut Gibbon, objek merupakan perangkat yang tersulit karena disaring melalui persepsi objek seseorang dengan pengertian alami atau termediasi untuk pengertian yang alami (seperti perwujudan struktur molekular yang termediasi melalui sebuah mikroskop elektron untuk persepsi grafis). Setidaknya, ada indikasi hubungan antara istilah dengan definisi dan perangkat 
lain melalui hubungan antara konsep dengan definisi, karena keduanya memiliki hubungan dua arah, yakni hukum logika transifitas yang tetap menjaga hubungan definisi dan objek.

Dari dimensi linguistik, Valeontis dan Mantzari (2006) menyatakan bahwa yang mendasar dalam teori terminologi adalah perbedaan antara objek (misalnya, entitas dunia luar, konsep, yang mana adalah unit pengetahuan yang membentuk representasi mental objek) dan perancangan konsep (yang bisa berupa istilah, nama dan simbol). Selanjutnya konsep ditentukan oleh maksud relasi yang diacu konsep lain juga oleh definisi, yang membentuk deskriptif, metalinguistik yang memaknakan konsep.

Pada intinya, definisi memberikan fitur semantik penting dari suatu konsep dan juga fitur-fitur itulah yang membedakan konsep dari yang lain (Pavel, 2004).

\subsection{Karakteristik Konsep}

Konsep terdiri dari sejumlah karakteristik (Antia, 1999) sebagai berikut :

(1) Secara umum konsep itu adalah bahasa mandiri. Meskipun kata-kata yang ada menggambarkan konsep yang mungkin berbeda karena bahasa tidak sama atau kemungkinan berbeda karena faktor internal sebagai bawaan bahasa, yang dihasilkan dari pengalaman dan pendidikan dibandingkan dengan keberadaannya seperti itu.

(2) Konsep adalah mental atau realitas representasi logika. Dalam pengertian ini semua konsep adalah abstrak dan murni ada secara mental, tapi ia mengatur cara menjadikan pikiran manusia untuk mengklasifikasi dan untuk memahami persepsi pikiran.

(3) Konsep berisi sejumlah karakteristik. Realitas 'gambar mental' yang diklasifikasi menurut karakteristik yang memungkinkan untuk mengklasifikasi objek lain atau konsep yang sama, mirip atau yang berbeda sekalipun (dengan semua subkelompok dari kelompok yang ada).

(4) Konsep dinegosiasi dalam komunitas pengetahuan. Sebagai contoh dalam bidang khusus menyangkut kepentingan semua ahli harus memiliki 'gambar mental' yang sama terhadap sebuah objek agar terdapat fitur dan karakteristik yang disepakati dalam tugas mereka. Sebaliknya, sebagai ilutrasi sederhana, misalnya seorang ahli dapat berbicara tentang 'buah' sementara yang lain membahas warna 'merah' merujuk kepada kesamaan realitas. 
(5) Konsep terkait dengan konsep-konsep yang lain. Tidak ada 'gambar mental' yang berdiri sendiri meskipun terdapat hubungan dengan konsep lain.

(6) Konsep tidak membutuhkan simbol, tapi menghubungkan simbol-simbol sebagai alat komunikasi. Jika seseorang memperhatikan sebuah kata yang menandakan suatu konsep sebagai simbol untuk konsep, hal ini telah tercakup oleh kemandirian bahasa konsep. Hal ini juga benar untuk rumus matematis dan kesepakatan simbol lain berkenaan dengan kearbitrarian. Keberadaan konsep tanpa adanya simbol yang merepresentasikan dapat dibayangkan. Namun, jika hal ini tidak mungkin untuk diberikan contoh disini, akan terjadi kontradiksi secara otomatis terhadap hal yang tidak menghubungkan simbol - dalam kasus seperti ini, maka deskripsi dapat difungsikan sebagai simbol.

Dengan demikian, sistem konsep merupakan dasar terminografi dwibahasa. Sekali ditetapkan, maka sistem konsep dari dua bahasa dapat di padukan-posisinya berada di antara satu dengan yang lain-kemudian dinyatakan untuk mengidentifikasi padanan di antara istilah untuk merepresentasikan konsep yang sama dalam dua bahasa yang berbeda (Austermühl, 2010).

\subsection{Pemahaman Konsep menjadi Dasar Penerjemahan Terminologi}

Mengapa para penerjemah perlu memahami konsep yang berada dibalik sebuah istilah? Sebenarnya, mereka tidak harus memahami konsep tapi mereka harus meyakinkan bahwa mereka punya istilah yang benar yang terbentuk dalam bahasa target agar calon pembaca akan mampu memahami teks. Untuk mewujudkan hal tersebut, maka mereka harus memahami sebaik mungkin ranah pekerjaan yang mereka lakukan (Gibbon, 1999).

Mari kita lihat sebagai contoh, sebagaimana yang dikutip dari Gibbon. "Sebuah buku panduan teknis yang diterjemahkan dari bahasa Inggris ke bahasa Jerman. Pada panduan tersebut terdapat istilah 'york'. Menurut kamus menjelaskan sebagai berikut :

“yoke

1. (for oxen) Joch nt; (for carrying pails) Trag)joch nt, Schultertrag f.

2. pl-(pair of oxen) Joch, Gespann nt.

3. (fig: oppression) Joch nt. to throw off the rudas Joch abschütteln.

4. (on dress, blouse) Passe; (on pullover also) Joch nt.

... " (Terrel dkk., 1991dalam Gibbon, 1999). 
74| Mabasan - Vol. 5, No. 1, Januari-Juni 2011

Hasil terjemahan yang mana benar? Anggap saja ada sebuah kalimat yang bunyinya seperti “ Baju yang mempunyai model hati ganda berbentuk blus dengan ukuran lebar $10 \mathrm{~cm}$ 'The shirt has a double heart-shaped yoke of $10 \mathrm{~cm}$ width' ". Penerjemah dalam hal ini bisa mengabaikan tiga makna yang pertama. Namun, bisakah dia menjamin kebenaran makna yang keempat yang diambil? Apakah pernyataan untuk ranah baju 'shirt' sama dengan ranah rok panjang 'dress, blouse'? Hal ini bisa beda adanya karena yoke "berbentuk-hati ganda". Adakah bagian yang mirip untuk switer 'pullover' dan blus? Masalah seperti ini dapat menimbulkan teks yang lucu atau janggal bila si penerjemah tidak bisa menentukan dengan benar. Terjemahan untuk teks semacam itu bisa seperti berikut: "Das Hemd hat ein doppeltes herzförmiges Joch, $10 \mathrm{~cm}$ breit" or "Das Hemd hat eine $10 \mathrm{~cm}$ breite, doppelte herzförmige Passe". Jika si penerjemah mempunyai bank istilah untuk ranah shirt maka mungkin saja baginya bisa lebih mudah. Di sana ia bisa temukan sesuatu yang mirip dengan gambar seperti berikut:

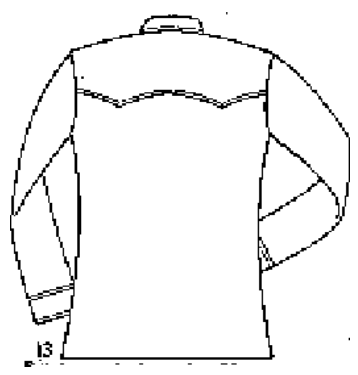

Gambar 3 : Tampak belakang " york” dengan model bentuk hati dobel atau ganda 'Rücken mit doppelter Herzpasse,'

\subsection{Pendekatan Adopsi melalui Aneka Padanan}

Pemertahanan makna konsep menjadi salah satu dimensi dalam aktivitas penerjemahan melalui pendekatan adopsi, terutama dalam istilah teknis seperti yang dijelaskan pada segitiga semiotik. Pada bagian ini dapat diuraikan pendekatan adopsi dalam pemadanan, dan lebih lanjut terkait dengan pemakaian kata serap dan kata adopsi mempunyai substansi makna yang sama dalam hal pemakaian unsur bahasa asing (lihat KBBI), maka kedua kata tersebut identik dalam artikel ini.

Berkaitan dengan penekanan di atas, maka unsur bahasa asing yang diserap ke dalam bahasa Indonesia harus mempertajam daya ungkap pemakai bahasa Indonesia dan memungkinkan orang menyatakan makna konsep atau gagasan secara tepat (Sofyan, 2004). 
Istilah Teknis dan Permasalahannya dalam Penerjemahan (Muhamad Nur)

\section{Pembahasan}

\subsection{Contoh Serapan Asing di Indonesia dan Kasus Negara Lain}

Berikut ini contoh serapan asing sebagaimana yang dikutip dari Sofyan, bahwa kata condominium yang belum lama terdapat dalam budaya Indonesia diserap ke dalam bahasa Indonesia dengan penyesuaian ejaan menjadi kondominium. Jadi penerjemahan itu dilakukan berdasarkan konsep makna istilah yang dikandungnya, bukan berdasarkan makna kata demi kata. Contoh penerjemahan serupa terjadi pada kata supermarket yang dipadankan dengan pasar swalayan.

Harus diakui bahwa pemadanan kata real estate dilakukan setelah kata itu banyak digunakan, termasuk padanan kata untuk nama kawasan. Sebagai akibatnya, orang sempat berpikir bahwa kata itu tidak memiliki padanan. Hal yang lazim terjadi ialah bahwa kata asing yang tidak berpadanan itu diserap dengan penyesuaian ejaan. Itu sebabnya orang mengindonesiakan real estate menjadi realestat. Bentuk kata yang terakhir itulah yang kemudian dipilih oleh para pengusaha di bidang pembangunan untuk rumah tinggal walaupun kata lahan yasan memiliki makna konsep yang sama.

Yang dijadikan dasar analogi lesapnya fonem e diakhir kata itu ialah penyerapan accurate, chocolate, conglomerate, dan dictate yang masing-masing menjadi akurat, cokelat, konglomerat, dan diktat. Jadi, lafal realestat sama dengan lafal pada kata akurat, cokelat, konglomerat, dan diktat, tidak dilafalkan [akuret], [coklet], [konglomeret], dan [diktet]. Selanjutnya, realestat ditulis menjadi satu kata (berbeda dari bentuk asalnya) karena mengacu pada serapan kudeta dari kata coup d'etat, dan prodeo dari pro deo (Sofyan, 2004).

Masih menurut Sofyan, kosakata serapan itu dapat mengisi kerumpangan atau kekosongan konsep makna yang tidak ditemukan di dalam khazanah bahasa Indonesia. Di samping bentuk dan makna kata serapan itu, memang diperlukan kehadirannya dalam bahasa Indonesia untuk kepentingan pemerkayaan konsep-konsep makna yang dapat menunjang laju pertumbuhan dan perkembangan ilmu pengetahuan dan teknologi Indonesia menatap masa depan.

Fenomena yang sama juga terjadi pada salah satu bahasa resmi Afrika Selatan 'isiNdebele' atau dalam bahasa Inggrisnya Ndebele. Akibat kontak langsung yang kurang cocok dengan terminologi yang sesuai dengan konsepkonsep bahasa asing dalam bahasa isiNdebele, kosakata bahasa ini ditingkatkan melalui peminjaman, baik dari bahasa lokal Afrikaans maupun dari bahasa Inggris. Sebagaimana yang dikutip dari Mahlangu (2007), bahwa bahasa 
76| Mabasan - Vol. 5, No. 1, Januari-Juni 2011

isiNdebele telah mengadopsi sejumlah leksikon dari bahasa lokal Afrikaans dan bahasa Inggris yang terdapat dalam berbagai bidang, seperti pendidikan, agama pertanian, industri, kesehatan, dan sebagainya. Pengembangan leksikon ini bahkan telah mengganti kosakata asli.

Contoh:

$\begin{array}{lll}\text { isikolo } & \text { 'school' } & (<\text { Afr: skool }) \\ \text { i-ofisi } & \text { 'office' } & (<\text { Eng }) \\ \text { utitjhere } & \text { 'teacher' } & (<\text { Eng }) \\ \text { iraba } & \text { 'rubber' } & (<\text { Eng }) \\ \text { iphepha } & \text { 'paper' } & (<\text { Eng })\end{array}$

Formalisasi pendidikan pada masyarakat Afrika melalui medium bahasa Inggris dan Afrikaans terdapat dalam sejumlah banyak istilah-istilah yang diperkenalkan dan diadopsi ke dalam bahasa resmi Afrika. IsiNdebele mengadopsi lebih banyak jumlah istilah pendidikan dari bahasa Inggris dibandingkan dengan bahasa Afrikaans. Bahasa Afrikaans ini merupakan bahasa Jermanik Barat yang dituturkan oleh para pendatang Afrikaner dan budak yang dibawa ke daerah Cape Town oleh Kompeni Hindia Belanda (wikipedia.org/25/04/2011)

\subsection{Contoh Serapan Bahasa Asing (Inggris) dari Bahasa Indonesia}

Contoh serapan pada bagian ini tidak termasuk istilah teknis, tapi sebagai gambaran dalam konteks pemertahanan makna konsep suatu bahasa terhadap bahasa lain, yakni adopsi bahasa Inggris dari bahasa Indonesia, baik melalui adaptasi ataupun pinjaman murni. Data ini diadaptasikan dari situs wikipediaensiklopedia internet-yang berhubungan dengan Binatang, Pepohonan dan Tanaman, Makanan, Buah-buahan, Pakaian Tradisional, Alat Musik, Kapal dan Senjata: 
Istilah Teknis dan Permasalahannya dalam Penerjemahan (Muhamad Nur)

Daftar kata serapan menurut katagori

\begin{tabular}{|c|c|c|}
\hline Katagori & Bahasa Indonesia & $\begin{array}{l}\text { Bahasa Asing } \\
\text { (Inggris) }\end{array}$ \\
\hline \multirow{5}{*}{ Binatang } & Kasuari & Cassowary \\
\hline & Kakatua & Cockatoo \\
\hline & Tapir & Tapir \\
\hline & Duvung & Dugong \\
\hline & Orangutan & Orangutan \\
\hline \multirow{7}{*}{$\begin{array}{l}\text { Tanaman dan } \\
\text { Pepohonan }\end{array}$} & Bambu & Bamboo \\
\hline & Padi & $P a d d y$ \\
\hline & Pandan & Pandanus \\
\hline & Rotan & Rattan \\
\hline & Sagu & Sago \\
\hline & Cempedak & Cempedak \\
\hline & Kapuk & Kapok \\
\hline \multirow{3}{*}{ Makanan } & Agar & Agar \\
\hline & Sate & Satay \\
\hline & Tempe & Tempeh \\
\hline \multirow{4}{*}{ Buah-buahan } & Durian & Durian \\
\hline & Manggis & Mangosteen \\
\hline & Rambutan & Rambutan \\
\hline & Salak & Salak atau Zalacca \\
\hline \multirow{3}{*}{$\begin{array}{l}\text { Pakaian } \\
\text { Tradisional }\end{array}$} & Batik & Batik \\
\hline & Koteka & Koteka \\
\hline & Sarung & Sarong \\
\hline \multirow{3}{*}{ Alat Musik } & Angklung & Angklung \\
\hline & Gamelan & Gamelan \\
\hline & Gong & Gong \\
\hline Kapal & Perahu & Proa \\
\hline \multirow{2}{*}{ Senjata } & Keris & Kris \\
\hline & Parang & Parang \\
\hline
\end{tabular}

Diadaptasi dari http://en.wikipedia.org/wiki/List_of_English_words_ of_Indonesian_origin

\subsection{Contoh Analisis Struktur semantik Istilah Mouse}

Pada bagian ini dapat diuraikan satu contoh analisis istilah di bidang teknologi informasi, yakni istilah mouse dalam bahasa sumber (BS) yang dipadankan menjadi tetikus bahasa target (BT). Padanan ini merupakan hasil rumusan TIM Inpres Nomor 2 Tahun 2001, tentang Panduan Pembakuan Istilah Teknis Aplikasi Komputer terhadap 629 item istilah teknis komputer. Kemudian dalam analisis ini, penulis merujuk kepada analisis struktur semantik yang digagas oleh Larson (1998:29) berdasarkan parameter komponen dan dipadu dengan teori segitiga semiotik tambahan yang digagas oleh ahli 
terminologi Suonuuti (1997) berdasarkan komponen konsep, objek, istilah dan definisi sebagaimana yang dapat diuraikan sebagai berikut :

Istilah teknis : Mouse

Definisi BS : a small electronic device attached to a computer that is moved by hand to control the position of the cursor on screen (ODC, pp. 235).

Sebuah alat elektronik yang dicantolkan pada komputer kemudian digerakkan oleh tangan untuk mengontrol posisi kursor pada layar (Oxford Dictionary of Computing (ODC), Pyne dan Tuck, 235: 1996)

Padanan BT : Tetikus

Definisi : peranti periperal pada komputer yang menyerupai tikus, gunanya, al; untuk memindahkan letak pandu di jendela tampilan (KBBI, pp. 1188)

Rekomendasi : Maus

Analisis Komponen Makna

\begin{tabular}{|c|c|c|c|c|}
\hline \multirow{2}{*}{\multicolumn{2}{|c|}{ PARAMETER }} & $B S$ & \multicolumn{2}{|c|}{$B T$} \\
\hline & & mouse & Tetikus & maus \\
\hline$B E N D A$ & alat elektronik & + & - & + \\
\hline PERISTIWA & $\begin{array}{l}\text { dicantol, digerakkan, } \\
\text { konrol }\end{array}$ & + & - & + \\
\hline ATRIBUT & oleh tangan, pada layar & + & - & + \\
\hline RELASI & oleh & + & - & + \\
\hline
\end{tabular}

Mencermati analisis komponen makna di atas, sebutan tetikus sebagai padanan untuk istilah mouse adalah tidak sesuai dengan konsep. Sebutan tetikus menurut definisi KBBI dapat dianalisis, dan definisi tersebut hanya mengilustrasikan bagaimana fungsi atau aktivitas mouse. Sebutan tetikus tidak dapat mengungkap dan mencakup ide mouse yang mendasari konsepnya dalam bahasa sumber. Fenomena yang sama juga terjadi dalam bahasa Rumania, seperti yang diungkap oleh Teleoaca (2004), bahwa penerjemahan untuk komponen leksikon internet atau web menunjukkan tugas yang sangat sulit karena kedua istilah tersebut termasuk leksikon yang konsepnya tidak dikenal (non-lexicalized concept) dalam bahasa target. Masih menurut Teleoaca, istilah 
internet atau web itu dirasakan bermasalah di antara pengguna dan tidak terdapat padanan dalam bahasa kami (Rumania), bahkan menurutnya juga terjadi hal yang sama dalam bahasa Spanyol, German, Perancis dan Portugis. Maka terjemahan secara literal, seperti istilah /mousel (bahasa Inggris) menjadi Itetikus/ (bahasa Indonesia) tidak cocok dalam konteks bahasa target (Nur: 2008), sebagaimana halnya dalam bahasa Rumania istilah /mousel menjadi Ifolosestel atau /clic pel (Teleoaca: 2004). Pada umumnya kita tahu bahwa istilah mouse dan konsepnya tidak dimiliki oleh bahasa target, hingga istilah ini dikenal oleh masyarakat pengguna-masyarakat Indonesia.

Dalam hubungannya dengan gagasan kajian ini, pendekatan untuk pengungkapan istilah teknis dalam bahasa target, sebutan maus dapat direkomendasikan sebagai padanan yang akurat untuk istilah mouse dengan mengacu kepada pendekatan adopsi, berdasarkan segitiga semiotik. Keempat komponen dalam segitiga semiotik tersebut juga harus dimiliki oleh bahasa sasaran dalam aktivitas penerjemahan.

Pendekatan tersebut juga sesuai dengan gagasan Sugono (2003:127) yang mengatakan bahwa istilah mouse menetapkan dua alternatif padanan, yakni sebutan tetikus dan maus, bandingkan dengan senarai padanan istilah teknis komputer (baca TIM Inpres no. 2/2001) yang hanya menyediakan sebutan tetikus saja. Namun, gagasan Sugono tampak inkonsistensi dan bertentangan dengan segitiga semiotik menyangkut pemberian dua alternatif padanan untuk istilah mouse ke dalam bahasa Indonesia karena ada pilihan lain sebutan tetikus di samping sebutan maus.

Dengan demikian, ekspresi konseptual harus menjadi ukuran strategi pemadanan istilah teknis dalam aktivitas penerjemahan. Untuk dapat melakukan hal ini secara linguistik, peminjaman istilah melalui adaptasi merupakan strategi yang tepat, misalnya melalui penyesuaian ejaan atau tulisan, disamping peminjaman murni. Peminjaman murni sebagaimana yang dikutip dari Nur (2008:38) dapat dilakukan sebagai alternatif bila peminjaman melalui adaptasi tidak mungkin dilakukan dalam kegiatan penerjemahan karena alasan faktorfaktor linguistik, seperti istilah bit (BS) menjadi bit (BT), dan digit (BS) menjadi digit (BT) tidak mengalami perubahan baik aspek fonetik maupun aspek semantiknya. 


\section{Simpulan}

Bahasa berperan penting dalam upaya pengembangan dan penyebarluasan ilmu. Setiap penelitian ilmiah tidak dapat dilaksanakan tanpa menggunakan bahasa, matematika (sarana berpikir deduktif), dan statistika (sarana berpikir induktif) sebagai sarana berpikir, seperti yang disampaikan oleh Sarwono dan Pardede.

Dalam penelitian dan komunikasi ilmiah, setiap ilmuwan perlu mengembangkan dan memahami bahasa (terutama jargon-jargon akademis dan terminologi khusus) yang digunakan dalam bidang yang ditekuni. Tanpa bahasa yang mereka pahami bersama, kesalahpahaman akan sulit dihindari dan mereka tidak dapat bersinergi untuk mengembangkan ilmu, seperti yang ditegaskan oleh Pardede.

Istilah teknis sebagai bahasa bidang khusus hendaknya dipahami dan diterapkan sebagaimana mestinya menurut konsep linguistik. Seperti halnya kata term dalam bahasa Inggris sendiri, yang berasal dari bahasa Latin terminus diadopsi melalui pendekatan adaptasi menurut unsur linguistik. Oleh karena itu, untuk mempertahankan makna konsep dan komponennya sebagai bahasa khusus dalam bidang tertentu, kata term secara etimologi dapat kita maknai sebagai jabaran..."dewa dari tanah bertanda dan batu pembatas pada zaman Romawi Kuno dan areal yang dilindungi kesakralannya, seperti tersebut di atas.

Mencermati pesatnya perkembangan dan penggunaan istilah-istilah sains dan teknologi, baik melalui informasi, komunikasi, media, bahkan secara lisan, maka pendekatan secara linguistik hendaknya ditetapkan regulasinya dengan merujuk kepada ketentuan internasional secara utuh, seperti Standardisasi Terminologi Internasional, ISO, Panduan Terminologi, dan para ahli terminologi.

\section{Daftar Pustaka}

Alwi, Hasan. 2007. Kamus Besar Bahasa Indonesia-KBBI. Edisi Ke-3. Jakarta: Balai Pustaka.

Antia, dalam Gibbon. 1999. Terminology for Spoken Language Systems. Thorsten TrippelBielefeld. Germany: Universität Bielefeld.

Сєліванова, 2010, dalam Rusko dan Santalka, 2010. English Computing Terminology as a System. Lithuania: Vilnius. 
Istilah Teknis dan Permasalahannya dalam Penerjemahan (Muhamad Nur) $\mid \mathbf{8 1}$

Filipoviçc, Jelena dan Jovan Filipoviçc. 2005. General Trends in Standardisation of Scientific Terminology in Serbian: A Critical Analyses of The States of Affairs. Serbia: Belgrade University.

Frank, Austermühl. 2010. A Collaborative approach to the Teaching of Terminology Management.

Gibbon, Dafydd. 1999. Terminology for Spoken Language Systems. Thorsten Trippel Bielefeld. Germany: Universität Bielefeld.

Лейчик. 2007, dalam Rusko dan Santalka. 2010. English Computing Terminology as a System. Lithuania: Vilnius.

Keller N. 2010. Translation in Transition-Integrating Multi-Word Terms in Terminology Management Systems. Germany: Wissenschaftlicher Verlag Trier- T2IN.

Larson, L.Mildred. 1998. Meaning-Based Translation, $2^{\text {nd }}$ Ed., New York: University of America, Inc.

Lionhardt, Christine. 2001. Handbook of Terminology; Terminology and Standardisation Translation Bureau. Canada: Minister of Public Works and Government Services.

Mahlangu S. Katjie. 2007. Semantic and Morphological Aspects of Adoption of Afrikaans and English Loanwords into isiNdebele. Master Thesis. University of Pretoria, South Africa.

Matsuda, Makiko dkk. 2008. "Technical Terminology in Asian Languages: Different Approaches to Adopting Engineering Terms" The $6^{\text {th }}$ Workshop on Asian Languages Resources. Japan.

Nur, Muhamad. 2008. Translation and Signification Analyses of Computer Technical Terms. Master Thesis. Denpasar: Udayana University.

Pardede, Parlindungan. 2010. Ilmu dan Bahasa. Tersedia pada http://www.tcpdf.org. Diakses tanggal 17/10/2010.

Pavel, Silvia. 2004. Terminology Tutorial. Canada: Translation Bureau.

Pinchuck, Isadore. 1977. Scientific and Technical Translation. London: Andre Deutsch Limited.

Rusko, Tatjana dan Santalka. 2010. English Computing terminology as a System. Vilnius Gediminas Technical University. Lithuania: Vilnius. 
Sager, 1990, dalam Gibbon, Dafydd. 1999. Terminology for Spoken Language Systems. Thorsten Trippel Bielefeld. Germany: Universität Bielefeld.

Sarwono, 2006. dalam Pardede, Parlindungan. 2010. Ilmu dan Bahasa. Tersedia pada http://www.tcpdf.org. Diakses tanggal 17/10/2010.

Skuce, Douglas dan Meyer Ingrid. Concept Analysis and Terminology; A Knowledge-based Approach to Documentation. Diakses tanggal 29/07/2010.

Sofyan, A.Nero.2004. Aneka Padanan Serapan Asing dalam Bahasa Indonesia. Diakses tanggal 17/10/2010.

Sugono, Dendy. 2003. Pengindonesiaan Kata dan Ungkapan Asing. Edisi Kedua. Jakarta: Pusat Bahasa-Depdiknas.

Sugono, Dendy. 2007. Pedoman Umum Pembentukan Istilah. Edisi ke-3. Cetakan ke-4. Jakarta: Pusat Bahasa.

Teleoaca, Anca Irinel. 2004. "Internet and Cultural Concepts from a Translation Perspective Translation” Journal, Volume 8, No. 1, January 2004. Tersedia pada URL://accurapid.com/journal/27romania.html. Diakses tanggal 3/24/2007.

Terrel dkk. 1991 dalam Gibbon. 1999. Terminology for Spoken Language Systems. Thorsten Trippel Bielefeld. Germany: Universität Bielefeld.

Valeontis dan Muntzari. 2006. "The Linguistic Dimension of Terminology: Principle and Methods of Term Formation". 1st Athens International Conference on Translation and Interpretation Translation: Between Art and Social Science, 13-14 October 2006. Athens.

Wikipedia Bahasa Indonesia, Ensiklopedia Bebas. Bahasa Afrikaans. Tersedia pada http://id.wikipedia.org/wiki/Bahasa_Afrikaans/diakses 25/04/2011.

Wikipedia Bahasa Indonesia, Ensiklopedia Bebas. List of English words of Indonesian Origin. Tersedia pada http://en.wikipedia.org/wiki/List_of_ English_words_of_Indonesian_origin. Diakses tanggal 02/05/2011 